\title{
The effect of lidocaine on apoptotic neurodegeneration in the developing mouse brain
}

\author{
Ji-Hyun Lee ${ }^{1}$, Yong-Hee Park ${ }^{2}$, Hyun-Gul Song ${ }^{1}$, Hee-Pyoung Park ${ }^{1}$, Hee-Soo Kim ${ }^{1}$, \\ Chong-Sung Kim ${ }^{1}$, and Jin-Tae Kim ${ }^{1}$ \\ Department of Anesthesiology and Pain Medicine, ${ }^{1}$ Seoul National University Hospital, ${ }^{2}$ Chung-Ang University Hospital, Seoul, \\ Korea
}

Background: General anesthetics induce neuronal apoptosis in the immature brain. Regional anesthesia using local anesthetics can be an alternative to general anesthesia. Therefore, this study investigated the possible effect of lidocaine on neuronal apoptosis.

Methods: Fifty-one 7-day-old C57BL6 mice were allocated into control (group C), lidocaine (group L), lidocaine plus midazolam (group LM) and isoflurane (group I) groups. Group C received normal saline administration. Groups L and LM were injected with lidocaine ( $4 \mathrm{mg} / \mathrm{kg}$, subcutaneously) only and the same dose of lidocaine plus midazolam (9 $\mathrm{mg} /$ $\mathrm{kg}$, subcutaneously). Group I was exposed to $0.75 \mathrm{vol} \%$ isoflurane for $6 \mathrm{~h}$. After $6 \mathrm{~h}$, apoptotic neurodegeneration was assessed using caspase-3 immunostaining and terminal deoxynucleotidyl transferase dUTP nick-end labelling (TUNEL) staining.

Results: For the entire brain section, neuronal cells exhibiting caspase-3 activation were observed more frequently in group I than in group $\mathrm{C}(\mathrm{P}<0.001)$. In the thalamus, apoptosis of group $\mathrm{L}$ was more frequent than that of group $\mathrm{C}$ $(\mathrm{P}<0.001)$, but less freqent than that of groups $\mathrm{LM}$ and $\mathrm{I}(\mathrm{P}=0.0075$ and $\mathrm{P}<0.001$, respectively). In the cortex, group I experienced more apoptosis than group L and C (all Ps $<0.001$ ). On TUNEL staining, the difference in apoptosis between the lidocaine and control groups was marginal $(\mathrm{P}=0.05)$.

Conclusions: Lidocaine induced minimal apoptosis in the developing brain compared with isoflurane and lidocaine plus midazolam. However, we cannot fully exclude the possible adverse effect of subcutaneously administered lidocaine on the developing brain. (Korean J Anesthesiol 2014; 67: 334-341)

Key Words: Apoptosis, Brain, General anesthetics, Local anesthetics, Lidocaine, Mice.

Received: February 3, 2014. Revised: 1st, May 13, 2014; 2nd, June 30, 2014; 3rd, July 31, 2014. Accepted: August 8, 2014.

Corresponding author: Jin-Tae Kim, M.D., Ph.D., Department of Anesthesiology and Pain Medicine, Seoul National University Hospital, 101, Daehak-ro, Jongno-gu, Seoul 110-744, Korea. Tel: 82-2-2072-3661, Fax: 82-2-747-8142, E-mail: kimjintae73@dreamwiz.com

This is thesis for a Master's degree.

(c) This is an open-access article distributed under the terms of the Creative Commons Attribution Non-Commercial License (http:// creativecommons.org/licenses/by-nc/3.0/), which permits unrestricted non-commercial use, distribution, and reproduction in any medium, provided the original work is properly cited. 


\section{Introduction}

Recent animal studies have demonstrated that early exposure to general anesthetics or sedatives induces apoptotic neurodegeneration in the developing brain and results in memory/learning impairment [1-5]. In addition, several clinical studies have suggested that early and multiple exposures to general anesthesia are associated with poor neurodevelopmental outcomes [6-8]. Therefore, the demand for less neurotoxic alternatives has been rising in children.

Local anesthetics act mainly by inhibiting sodium influx through sodium-specific ion channels. Since the mechanism of local anesthetics differs from that of general anesthetics, local anesthetics may have different effects on the developing brain. It is reasonable to believe that regional anesthesia using local anesthetics would be an alternative method to avoid general anesthetic-induced neurotoxicity in some simple surgeries. However, several studies have shown a toxic effect on neuronal cells [912]. Lee et al. [12] revealed that tetracaine induces apoptosis in cortical astrocytes, and another study showed that lidocaine induces brain injury in adult rats [10]. Although local anestheticinduced neurotoxicity has been demonstrated no study identified the brain apoptosis after subcutaneous infiltration of local anesthetics and has compared it with general anesthetic-induced apoptosis in the developing brain.

Lidocaine is one of the most widely used local anesthetics in regional anesthesia. The purpose of this study was to evaluate the effect of lidocaine on neuronal apoptosis and to compare it with that of inhalational anesthetics in the developing mouse brain. Because children sometimes cannot withstand surgery under regional anesthesia only, a sedative such as midazolam is usually combined with regional anesthesia. Therefore, the effect of the combination of local anesthetics and sedatives on neurotoxicity was also evaluated.

\section{Materials and Methods}

\section{Animals and anesthesia treatment}

The experiments were approved by the Institutional Animal Care and Use Committee (No. 11-0232) of Seoul National University Hospital on March 1, 2012. Fifty-one 7-day-old (p7) C57BL6 mice weighing 2.5-3 g were studied because they are known to be most sensitive to neuroapoptosis caused by anesthetic agents such as gamma-aminobutyric acid (GABA) -mimetics or N-methyl-D-aspartate (NMDA) antagonists [4]. The mice were randomly divided into control (group C, $\mathrm{n}=15$ ), lidocaine (group $\mathrm{L}, \mathrm{n}=12$ ), lidocaine plus midazolam (group $\mathrm{LM}, \mathrm{n}=14$ ), and isoflurane (group I, $\mathrm{n}=10$ ) groups.

Group C was given normal saline $(10 \mu \mathrm{l} / \mathrm{g})$ subcutaneously (s.c.) [5], using a $30 \mathrm{G}$ needle. In group L, lidocaine was injected s.c. at a dose of $4 \mathrm{mg} / \mathrm{kg}$, which is a comparable to that used for regional nerve blocks in humans. Mice in group LM received lidocaine $4 \mathrm{mg} / \mathrm{kg}$ s.c. and midazolam $9 \mathrm{mg} / \mathrm{kg}$ s.c. The dose of subcutaneous midazolam was determined based on previous studies [2,4]. After subcutaneous administration of normal saline as in group $\mathrm{C}$, the mice in group I were placed in the anesthesia chamber and isoflurane $0.75 \mathrm{vol} \%$ was delivered to the chamber for $6 \mathrm{~h}$. A heat lamp was applied to avoid hypothermia throughout the experiment. If the breathing rate was decreased, the chamber was shaken to stimulate the mice in group I. After a single injection of neurotoxic agents, neuroapoptosis in the brain reached peak at a $5-6 \mathrm{~h}$ post-treatment in previous studies $[4,13]$. Therefore, 6 hours after drug administration, all of the pups were decapitated and the brains were extracted within $20 \mathrm{~s}$ and fixed with 10\% paraformaldehyde ( $\mathrm{pH} 7.4$ ) for $48 \mathrm{~h}$.

\section{Immunohistochemical study of activated caspase-3 (C-3A)}

The brains were histologically analyzed using paraffin-embedded sections. Before analysis, deparaffinization and antigen retrieval were performed using Dako Target Retrieval Solution (Dako, Glostop, Denmark). Sections were washed in deionized water, quenched for $5 \mathrm{~min}$ in a solution of $3 \% \mathrm{H}_{2} \mathrm{O}_{2}$ for endogenous blocking, and incubated for $30 \mathrm{~min}$ in rabbit antiactive caspase- 3 antiserum (D175, Cell Signaling Technology, Beverly, MA, USA) diluted 1 : 500 in blocking agent. Following incubation with D175 primary antibody, the sections were buffered and incubated for $30 \mathrm{~min}$ in secondary antibody (Dako EnVision+ System- HRP-labeled Polymer, anti-rabbit; Dako). Immunostaining was visualized using DAB chromogen (Dako) and counterstaining was performed using Mayer's hematoxylin. Positive staining was recognised under a light microscope as a diffuse brown color in the cytoplasm.

\section{Terminal deoxynucleotidyl transferase dUTP nick end labeling (TUNEL) staining}

To detect DNA fragmentation, TUNEL staining was performed using the ApopTag ${ }^{\circledR}$ Peroxidase in situ Apoptosis Detection Kit S7100 (Millipore, Billerica, MA, USA). After deparaffinization with xylene and graded concentrations of alcohol, the brain sections were exposed to proteinase $\mathrm{K}$ for $15 \mathrm{~min}$ at room temperature. Endogenous peroxidase activity was quenched with $3 \% \mathrm{H}_{2} \mathrm{O}_{2}$ in phosphate-buffered saline for $5 \mathrm{~min}$ at room temperature. Next, the sections were incubated with terminal deoxynucleotidyl transferase in a humidified chamber at $37^{\circ} \mathrm{C}$ for $1 \mathrm{~h}$. After incubation with anti-digoxigenin conjugate for $30 \mathrm{~min}$ at room temperature, peroxidase substrate $(0.05 \%$ diaminobenzidine, DAB) was applied for color development. The 
specimens were then washed with distilled water and counterstained with $0.5 \%$ methyl green for $10 \mathrm{~min}$ at room temperature. TUNEL-positive cells were deemed to be undergoing apoptosis.

\section{Cell counting}

The sagittal sections of the brain were used for evaluation of apoptosis $[4,13,14]$. The brain was cut $100 \mu \mathrm{m}$ from the midline in each hemisphere and sectioned sagittally in $4 \mu \mathrm{m}$ slices. For quantitative counts of C-3A-positive cells, the first sagittal section from each hemisphere was selected. PC-based image analysis software (LAS AF; Leica Microsystems CMS GmbH, Mannheim, Germany) interfaced with a Leica DM2500 microscope via a digital camera (Leica DFC280; Leica Microsystems Imaging Solutions Ltd., Cambridge, UK) was used for image analysis.

As described previously [4], a C-3A-positive cell was defined

\section{A}

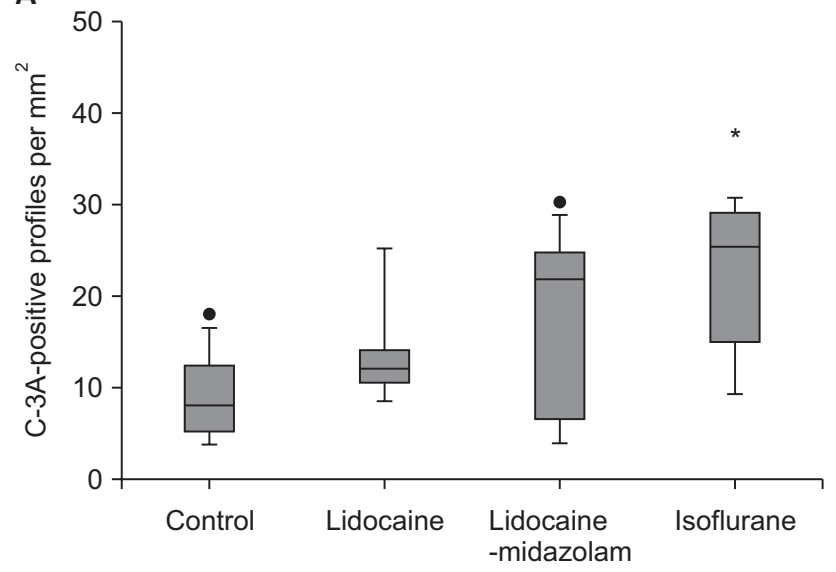

C

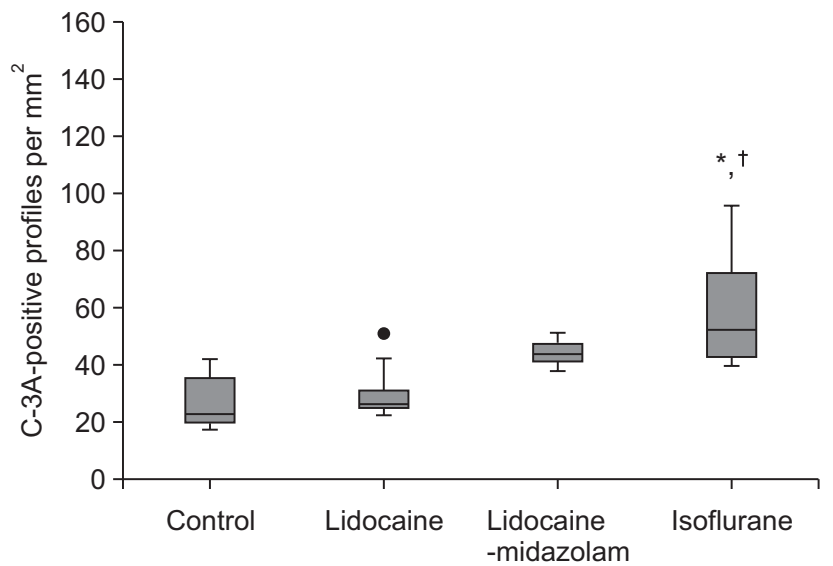

as a neuron with dendrites or a neuron larger than $8 \mu \mathrm{m}$. The total number of C-3A-positive cells in the entire area of the two sagittal sections was counted and divided by the total area of the two sections determined by the LAS software to calculate profile densities (apoptotic profiles per $\mathrm{mm}^{2}$ ) [4]. In addition, the densities were calculated for specific regions, such as the thalamus, cortex and caudate nucleus.

Two additional sagittal sections, which were also symmetric, were selected for TUNEL staining. The density of TUNEL-positive cells in the entire field was obtained. Quantitative analysis including cell counting was performed by an investigator who was blinded to the treatment conditions.

\section{Statistics}

All of the data were analyzed using SPSS statistics ver. 19 (SPSS, Chicago, IL, USA). Before analysis, a normality test was
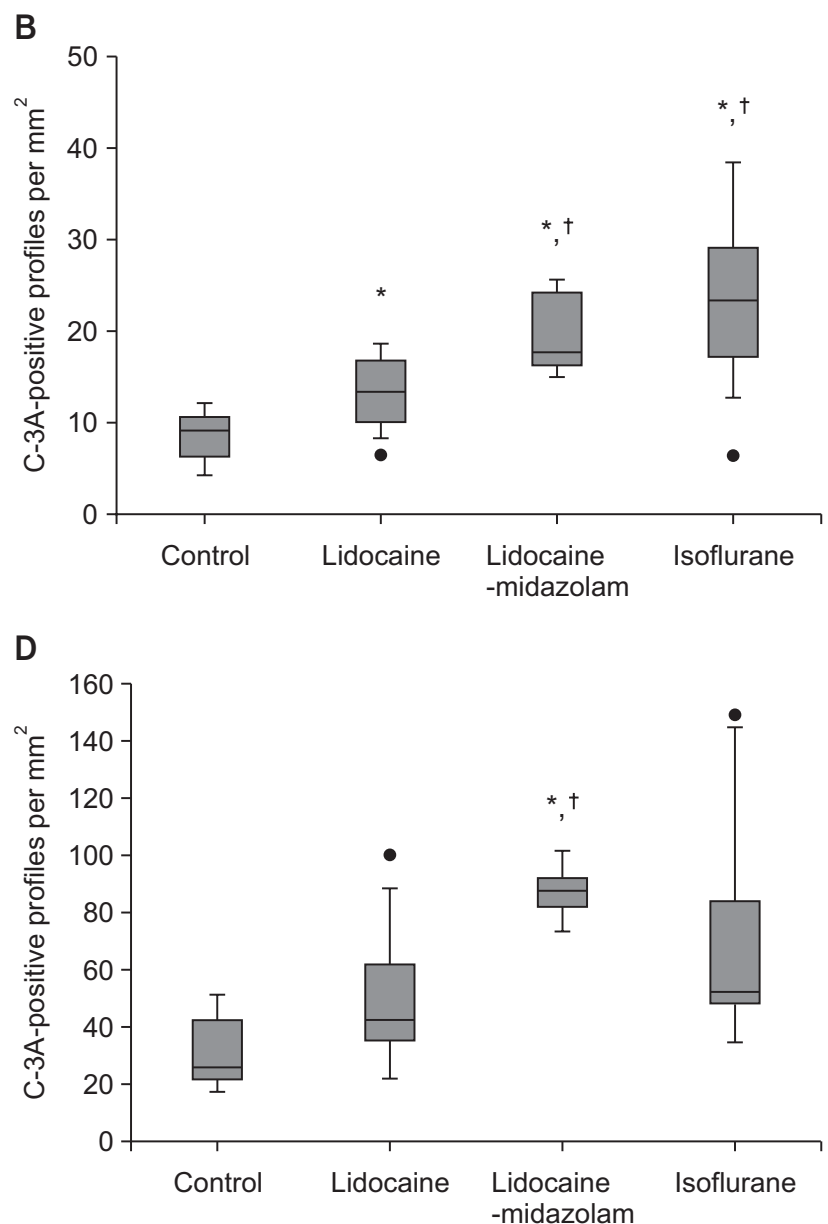

Fig. 1. Quantitative analysis of activated caspase-3 profile density. (A) Entire brain, (B) Thalamus, (C) Cortex, (D) Caudate nucleus. Number in each group: control $(n=15)$, lidocaine $(n=12)$, lidocaine-midazolam $(n=14)$, isoflurane $(n=10)$. The Kruskal-Wallis test was performed, and post hoc analysis was performed using the Mann-Whitney $U$-test with Bonferroni correction. The thick lines represent the median values, boxes indicate the interquartile range, and whiskers represent the 10 th and 90 th percentiles, respectively. Black dots represent outliers. C-3A: activated caspase-3. $* \mathrm{P}<0.0083$ compared with the control group. ${ }^{\dagger} \mathrm{P}<0.0083$ compared with the lidocaine group. 
performed. If the data were normally distributed, the density of apoptotic cells was analyzed using one-way analysis of variance (ANOVA) and Dunnett's method for post hoc analysis. If the data did not follow a normal distribution, the Kruskal-Wallis test was performed and the Mann-Whitney U-test with Bonferroni correction was used. A P value or adjusted $\mathrm{P}$ value less than 0.05 were deemed to indicate statistical significance.

\section{Results}

Fifty-one C57BL6 p7 mice were included in the present study. The immunohistochemical data did not follow a normal distribution, whereas the TUNEL results were normally distributed.

\section{Immunohistochemical study of activated caspase-3 (C-3A)}

Fig. 1 shows the number of apoptotic cells per $\mathrm{mm}^{2}$ in the entire brain and each individual region (thalamus, cortex, and caudate nucleus). For the entire brain section, neuronal cells exhibiting caspase-3 activation were observed more frequently in group I than in group $\mathrm{C}(\mathrm{P}<0.001)$. Otherwise, no significant difference between the groups was observed.

There were some differences between the results in the entire section and those in specific regions. In the thalamus, apoptosis in group $\mathrm{L}$ was observed significantly more frequently than in group $\mathrm{C}(\mathrm{P}<0.001)$, but less than that in groups LM and I ( $\mathrm{P}=0.0075$ and $\mathrm{P}<0.001$, respectively) (Fig. 2). In the cortex, the mice in group I showed more apoptosis than those in groups
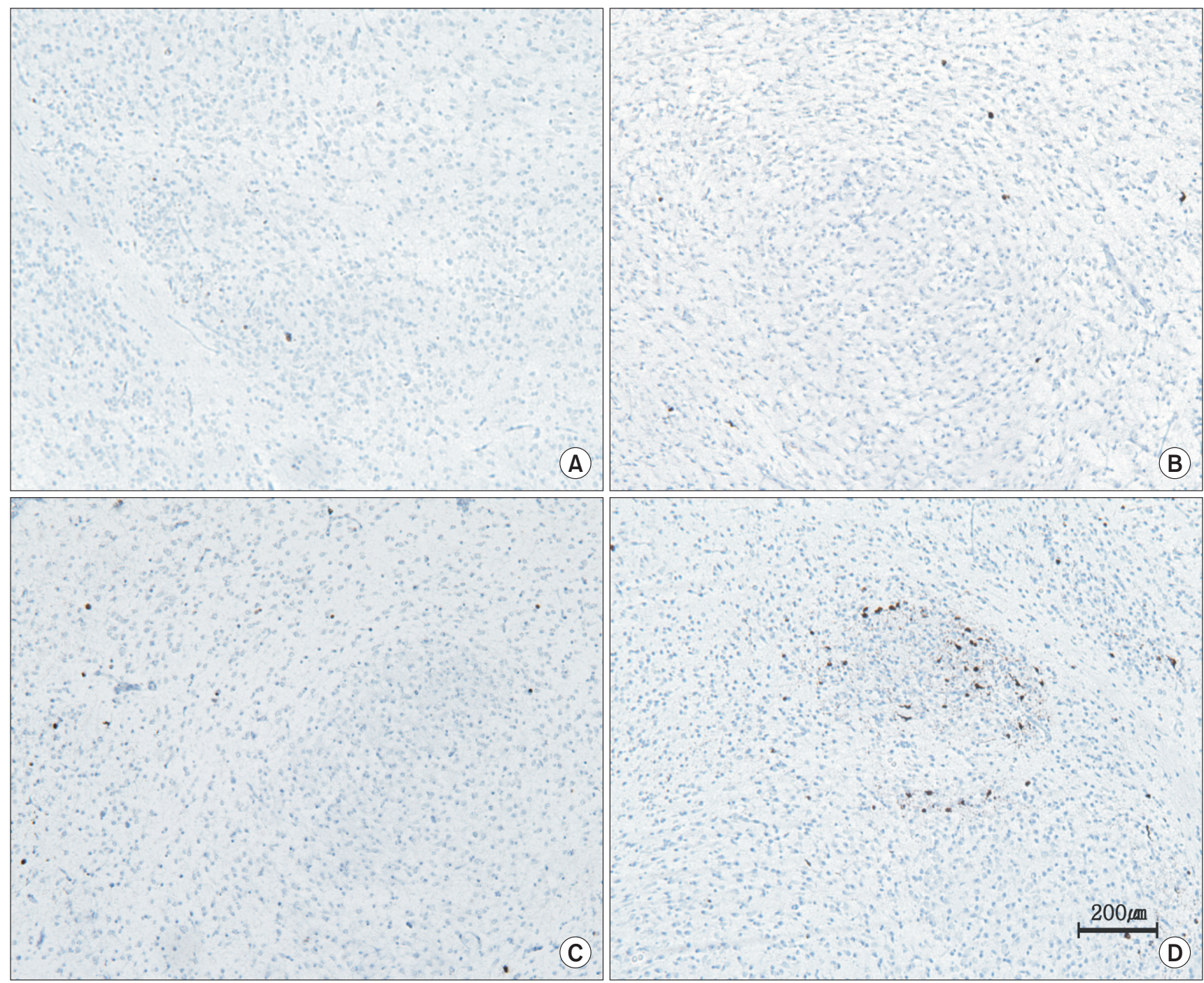

Fig. 2. Apoptosis in the thalamus confirmed by caspase-3 immunostaining. Dark brown-colored cell bodies are in the process of apoptosis. More neuronal apoptosis is observed in the lidocaine-midazolam and isoflurane groups compared with that in the control group. The isoflurane group also exhibits more apoptosis than the lidocaine group. Activated caspase-3 positive cells of the lidocaine group are significantly more frequent than those of the control group. (A) Control, (B) Lidocaine, (C) Lidocaine-midazolam, (D) Isoflurane group. 
$\mathrm{L}$ and $\mathrm{C}$ (all $\mathrm{P}<0.001$ ) (Fig. 3). In the caudate nucleus, apoptosis was observed more frequently in group LM than in groups $\mathrm{C}$ $(\mathrm{P}=0.002)$ and $\mathrm{L}(\mathrm{P}=0.006)$ (Fig. 4).

\section{TUNEL staining}

On TUNEL staining, the number of cells per $\mathrm{mm}^{2}$ undergoing DNA fragmentation was less in group $\mathrm{C}$ than in groups LM and $\mathrm{I}(\mathrm{P}=0.006$ and $\mathrm{P}=0.002$, respectively). Apoptosis in group I was also observed more frequently than in group $\mathrm{L}(\mathrm{P}=0.036)$ (Fig. 5).

\section{Discussion}

General anesthetics that act through GABA and NMDA receptors cause apoptotic neurodegeneration in the developing brain $[1-3,15]$. Local anesthetics can be substituted for general anesthetics, and the neurotoxicity of local anesthetics has been demonstrated in in vivo and in vitro studies [9-11,16]. A previous study showed the possibility of neuronal damage of brain cells by a single injection of lidocaine in adult rats [10]. However, a subconvulsive or convulsive dose was used in that study. Until now, no study has investigated the association between local anesthetics and brain apoptosis in the developing brain. Therefore, we evaluated the effect of local anesthetics on apoptotic neurodegeneration in the vulnerable immature brain using a single subcutaneous lidocaine dose. As expected, isoflurane and midazolam plus lidocaine induced apoptosis in the developing brain. Although lidocaine administration had a lesser apoptotic effect than isoflurane or lidocaine plus midazolam, our result showed that a possible adverse effect of lidocaine on the developing brain cannot be excluded.

The dose range of isoflurane was from 0.75 to $1.5 \mathrm{vol} \%$ in previous studies [1,17]. However, all four mice in the 1.0-1.5 vol\% isoflurane chamber died in our pilot study. Therefore, we used an isoflurane concentration of 0.75 vol\% during the experi-

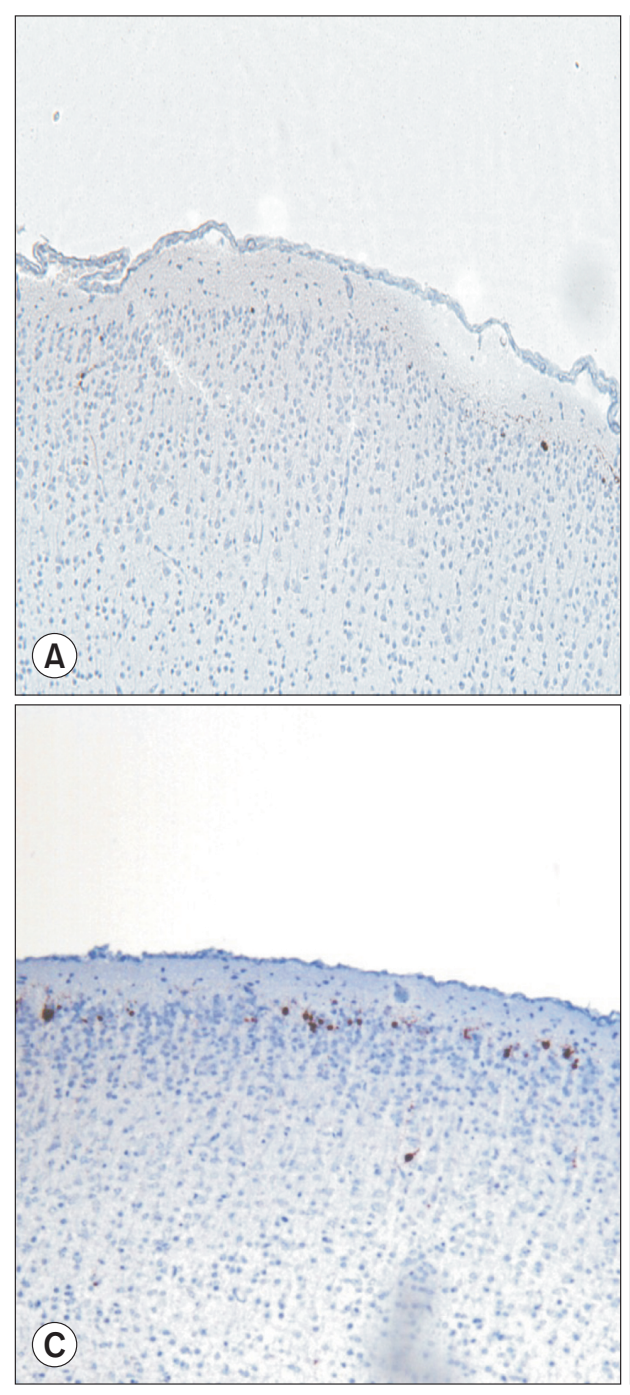

Fig. 3. Apoptosis confirmed by caspase-3 immunostaining in the cortex. Dark browncolored cell bodies are in the process of apoptosis. Activated caspase-3-positive cells are observed more frequently in the isoflurane group than in the control and lidocaine groups. (A) Control group, (B) Lidocaine group, (C) Lidocainemidazolam group, (D) Isoflurane group. 

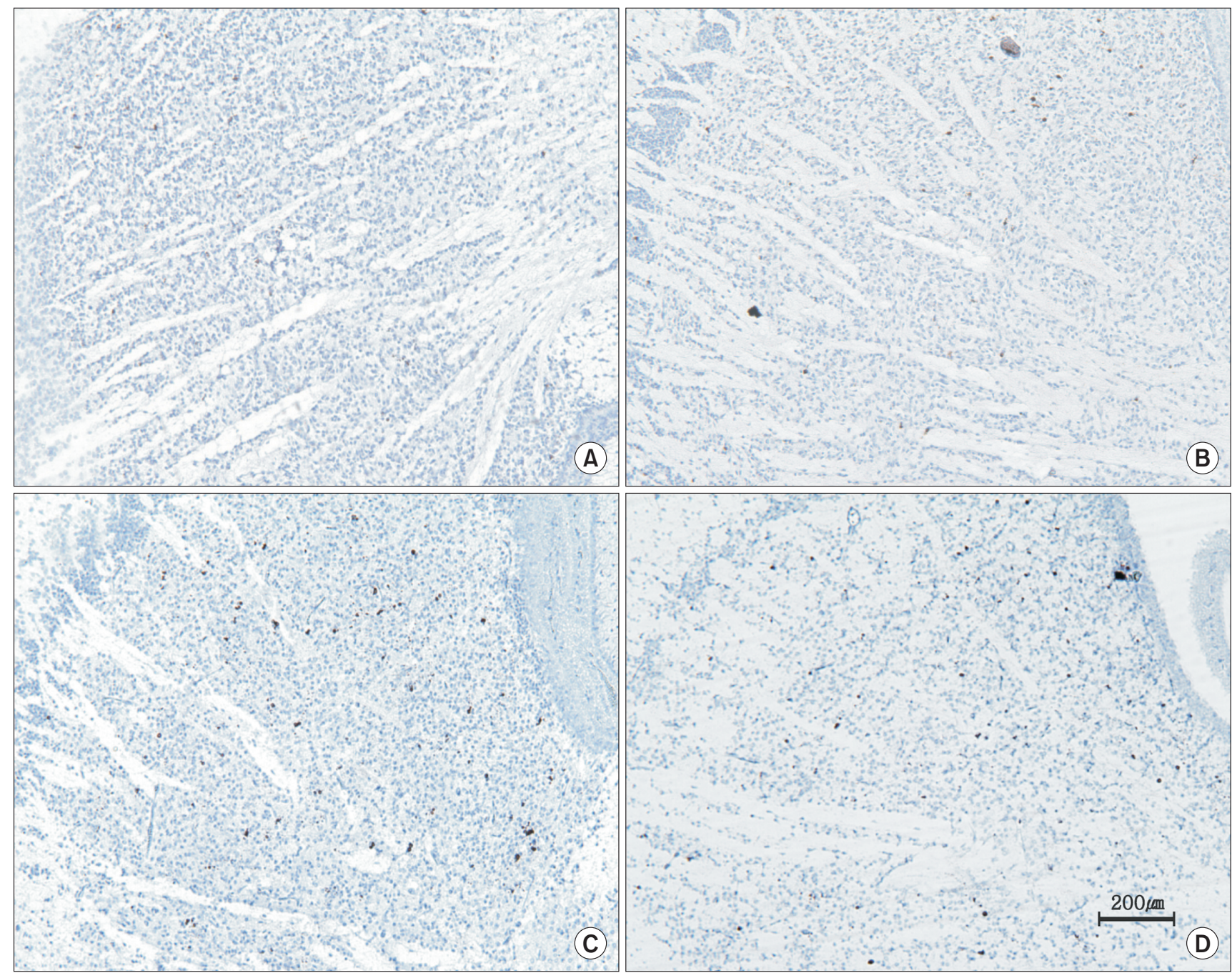

Fig. 4. Apoptosis confirmed by caspase- 3 immunostaining in the caudate nucleus. Dark brown-colored cell bodies are in the process of apoptosis. Apoptosis is observed more frequently in the lidocaine-midazolam group than in the control and lidocaine groups. (A) Control group, (B) Lidocaine group, (C) Lidocaine-midazolam group, (D) Isoflurane group.

ment. Midazolam $9 \mathrm{mg} / \mathrm{kg}$ s.c. induced significant neuroapoptosis in infant mice. This dosage was considered a sedating or subanesthetic dose for infant mice and was equivalent to the dose for a human infant $[2,4]$.

Lidocaine was not administered into the peritoneum because we wanted to evaluate the neurotoxic effect of subcutaneous lidocaine in the clinical practice of peripheral nerve block or field block. For lidocaine, it was important to identify an adequate dose that did not exceed the toxic dosage. Until now, no study has investigated the pharmacokinetics of single-shot subcutaneous lidocaine in 7-day-old (p7) C57BL6 mice. Since the allowable maximal dose of lidocaine for a regional nerve block is 5 $\mathrm{mg} / \mathrm{kg}$ in infants and children [18], we used a single bolus dose of $4 \mathrm{mg} / \mathrm{kg}$ s.c., which was not considered excessive compared with that of previous experiments concerning pharmacodynam- ics evaluation using rats with subcutaneous lidocaine $3-5 \mathrm{mg} / \mathrm{kg}$ for sciatic nerve block [19]. In addition, the median convulsive dose $\left(\mathrm{CD}_{50}\right)$ of lidocaine for mice was $289.4 \pm 13.4 \mathrm{mg} / \mathrm{kg}$ s.c. [20], suggesting that $4 \mathrm{mg} / \mathrm{kg}$ s.c. was a safe dose for a mouse.

By immunohistochemical staining, not only the entire region but also a particular part of the brain such as the thalamus, cortex and caudate nucleus, were examined. The densities of activated caspase- 3 positive cells in the cortex and caudate nucleus were greater than those in the entire region and in the thalamus, because of the vulnerability of these areas to anesthesia-induced cell death [2]. The number of apoptotic cells was similar between group $\mathrm{C}$ and group $\mathrm{L}$ in the cortex and caudate nucleus. However in the thalamus, lidocaine induced more apoptotic cell death. The TUNEL assay results showed a marginal $\mathrm{P}$ value of 0.05 for the difference between group L and group C. Accord- 


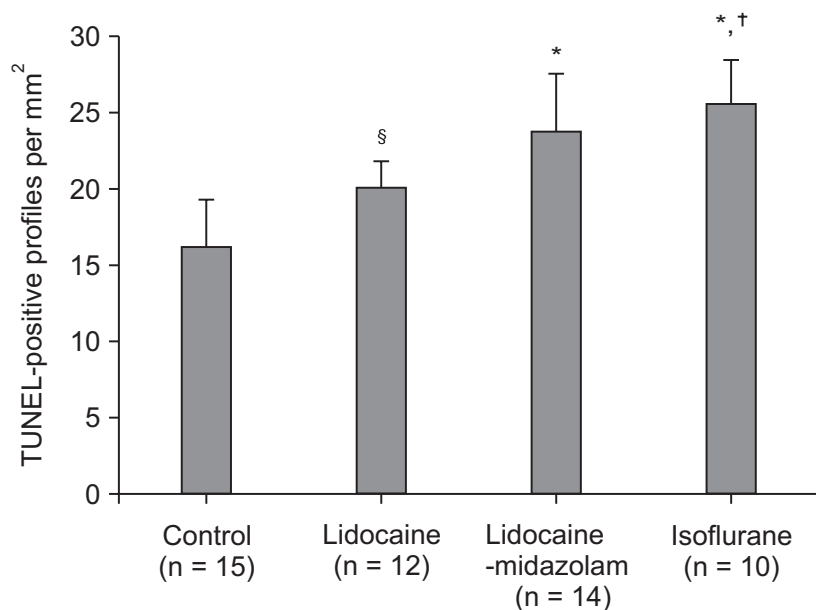

Fig. 5. Quantitative analysis of TUNEL staining profile density. The density of apoptotic cells was analyzed using one-way ANOVA and Dunnett method for post hoc analysis. Bars represent means and standard deviations. ${ }^{*} \mathrm{P}<0.05$ compared with control group, ${ }^{\dagger} \mathrm{P}<0.05$ compared with lidocaine group; ${ }^{\S} \mathrm{P}=0.05$ compared with control group.

ingly, we cannot exclude the possibility of lidocaine-induced neuroapoptosis.

Previous studies have also raised the possibility of local anesthetic-induced apoptosis [9-11,16,21-23]. Local anesthetics are sodium channel blockers that are thought to be neurotoxic at certain concentrations. However, the mechanism of neurotoxicity is not related to the blockade of the sodium channel [22,23]. Three mechanisms of local anesthetics-induced cell death have been suggested. First, lidocaine blocks $\mathrm{Ca}^{2+}$-ATPase in the endoplasmic reticulum, releasing $\mathrm{Ca}^{2+}$ from internal stores, and the change in $\mathrm{Ca}^{2+}$ homeostasis leads to neuronal apoptosis [24] as with isoflurane [25]. In one in vitro study, prevention of the lidocaine-induced increase in $\mathrm{Ca}^{2+}$ attenuated the lidocaine-induced neurotoxicity in the isolated rat dorsal root ganglion [21]. Second, activation of a kinase, such as p38 mitogen-activated protein kinase (MAPK), may mediate neurotoxicity [26]. Third, mitochondrial injury and caspase activation have been suggested to be mechanisms of the neuronal injury caused by local anesthetics [22].

There are several limitations in this study. First, permanent neuronal loss affecting neuronal stem cells was not investigated. Because the long term effect of anesthesia in pediatric patients is an important and controversial issue [8,27], additional studies are required to clarify this effect by evaluating behaviour or learning disabilities. Second, according to previous study, brain cell death increased with time, and persisted for at least 10 days after a single exposure to lidocaine [10]. However, we evaluated apoptosis only $6 \mathrm{~h}$ after treatment and the neurotoxic effect of lidocaine might be underestimated. Third, cardiopulmonary function was not evaluated, such as arterial blood gas analysis. Decreased cardiopulmonary function may be related to brain hypoxia and ischemia. We actually observed that some mice in group I had a slightly decreased respiration rate, and tried to restore respiratory function with external stimulation. In addition, although the anesthetic chamber was connected to a carbon dioxide absorbent, the concentration of carbon dioxide was not delicately controlled possibly affecting the result of the isoflurane group. Finally, gender-specific effects on neurotoxicity must be considered. Several studies have addressed the effect of sex hormones on the susceptibility to neurotoxic agents or gender differences in neuro-inflammation [28-30]. These studies demonstrated different responses to several neurotoxic agents, such as alcohol and bisphenol, between males and females. Therefore, lidocaine induced neurotoxicity may be influenced by this effect.

In summary, neuronal apoptosis was induced less by lidocaine alone compared than by isoflurane or lidocaine plus midazolam. However, we cannot exclude the potential adverse effect of lidocaine on neuronal apoptosis in the immature brain. Further research is needed to assess the clinical relevance and exact mechanism of brain apoptosis caused by lidocaine.

\section{Acknowledgments}

This study was supported by the grant SNUH 0420110080 from Seoul National University Hospital, Seoul, Korea.

\section{References}

1. Jevtovic-Todorovic V, Hartman RE, Izumi Y, Benshoff ND, Dikranian K, Zorumski CF, et al. Early exposure to common anesthetic agents causes widespread neurodegeneration in the developing rat brain and persistent learning deficits. J Neurosci 2003; 23: 876-82.

2. Nikizad H, Yon JH, Carter LB, Jevtovic-Todorovic V. Early exposure to general anesthesia causes significant neuronal deletion in the developing rat brain. Ann N Y Acad Sci 2007; 1122: 69-82.

3. Slikker W Jr, Zou X, Hotchkiss CE, Divine RL, Sadovova N, Twaddle NC, et al. Ketamine-induced neuronal cell death in the perinatal rhesus monkey. Toxicol Sci 2007; 98: 145-58.

4. Young C, Jevtovic-Todorovic V, Qin YQ, Tenkova T, Wang H, Labruyere J, et al. Potential of ketamine and midazolam, individually or in combination, to induce apoptotic neurodegeneration in the infant mouse brain. Br J Pharmacol 2005; 146: 189-97. 
5. Zou X, Patterson TA, Sadovova N, Twaddle NC, Doerge DR, Zhang X, et al. Potential neurotoxicity of ketamine in the developing rat brain. Toxicol Sci 2009; 108: 149-58.

6. Flick RP, Katusic SK, Colligan RC, Wilder RT, Voigt RG, Olson MD, et al. Cognitive and behavioral outcomes after early exposure to anesthesia and surgery. Pediatrics 2011; 128: e1053-61.

7. Ing C, DiMaggio C, Whitehouse A, Hegarty MK, Brady J, von Ungern-Sternberg BS, et al. Long-term differences in language and cognitive function after childhood exposure to anesthesia. Pediatrics 2012; 130: e476-85.

8. Wilder RT, Flick RP, Sprung J, Katusic SK, Barbaresi WJ, Mickelson C, et al. Early exposure to anesthesia and learning disabilities in a population-based birth cohort. Anesthesiology 2009; 110: 796-804.

9. Perez-Castro R, Patel S, Garavito-Aguilar ZV, Rosenberg A, Recio-Pinto E, Zhang J, et al. Cytotoxicity of local anesthetics in human neuronal cells. Anesth Analg 2009; 108: 997-1007.

10. Blas-Valdivia V, Cano-Europa E, Hernández-Garcia A, Ortiz-Butrón R. Hippocampus and amygdala neurotoxicity produced by systemic lidocaine in adult rats. Life Sci 2007; 81: 691-4.

11. Werdehausen R, Braun S, Essmann F, Schulze-Osthoff K, Walczak H, Lipfert P, et al. Lidocaine induces apoptosis via the mitochondrial pathway independently of death receptor signaling. Anesthesiology 2007; 107: 136-43.

12. Lee WY, Park CJ, Shin TJ, Yum KW, Yoon TG, Seo KS, et al. Only tetracaine and not other local anaesthetics induce apoptosis in rat cortical astrocytes. Br J Anaesth 2009; 103: 719-25.

13. Young C, Olney JW. Neuroapoptosis in the infant mouse brain triggered by a transient small increase in blood alcohol concentration. Neurobiol Dis 2006; 22: 548-54.

14. White LD, Barone S Jr. Qualitative and quantitative estimates of apoptosis from birth to senescence in the rat brain. Cell Death Differ 2001; 8: 345-56.

15. Beals JK, Carter LB, Jevtovic-Todorovic V. Neurotoxicity of nitrous oxide and ketamine is more severe in aged than in young rat brain. Ann N Y Acad Sci 2003; 993: 115.

16. Lopez-Galindo GE, Cano-Europa E, Ortiz-Butron R. Ketamine prevents lidocaine-caused neurotoxicity in the CA3 hippocampal and basolateral amygdala regions of the brain in adult rats. J Anesth 2008; 22: 471-4.

17. Loepke AW, Istaphanous GK, McAuliffe JJ 3rd, Miles L, Hughes EA, McCann JC, et al. The effects of neonatal isoflurane exposure in mice on brain cell viability, adult behavior, learning, and memory. Anesth Analg 2009; 108: 90-104.

18. Bernard JD. Regional anesthesia in children. In: Miller's Anesthesia. 7th ed. Edited by Eriksson LI, Fleisher LA, Wiener-Kronish JP: Philadelphia, Churchill Livingstone/Elsevier. 2010, pp 2519-55.

19. Nakamura T, Popitz-Bergez F, Birknes J, Strichartz GR. The critical role of concentration for lidocaine block of peripheral nerve in vivo: studies of function and drug uptake in the rat. Anesthesiology 2003; 99: 1189-97.

20. de Jong RH, Bonin JD. Local anesthetics: injection route alters relative toxicity of bupivacaine. Anesth Analg 1980; 59: 925-8.

21. Gold MS, Reichling DB, Hampl KF, Drasner K, Levine JD. Lidocaine toxicity in primary afferent neurons from the rat. J Pharmacol Exp Ther 1998; 285: 413-21.

22. Johnson ME, Uhl CB, Spittler KH, Wang H, Gores GJ. Mitochondrial injury and caspase activation by the local anesthetic lidocaine. Anesthesiology 2004; 101: 1184-94.

23. Sakura S, Bollen AW, Ciriales R, Drasner K. Local anesthetic neurotoxicity does not result from blockade of voltage-gated sodium channels. Anesth Analg 1995; 81: 338-46.

24. He H, Lam M, McCormick TS, Distelhorst CW. Maintenance of calcium homeostasis in the endoplasmic reticulum by Bcl-2. J Cell Biol 1997; 138: 1219-28.

25. Kindler CH, Eilers H, Donohoe P, Ozer S, Bickler PE. Volatile anesthetics increase intracellular calcium in cerebrocortical and hippocampal neurons. Anesthesiology 1999; 90: 1137-45.

26. Lirk P, Haller I, Colvin HP, Lang L, Tomaselli B, Klimaschewski L, et al. In vitro, inhibition of mitogen-activated protein kinase pathways protects against bupivacaine- and ropivacaine-induced neurotoxicity. Anesth Analg 2008; 106: 1456-64.

27. Kalkman CJ, Peelen L, Moons KG, Veenhuizen M, Bruens M, Sinnema G, et al. Behavior and development in children and age at the time of first anesthetic exposure. Anesthesiology 2009; 110: 805-12.

28. Alfonso-Loeches S, Pascual M, Guerri C. Gender differences in alcohol-induced neurotoxicity and brain damage. Toxicology 2013; $311: 27-34$.

29. Beronius A, Johansson N, Rudén C, Hanberg A. The influence of study design and sex-differences on results from developmental neurotoxicity studies of bisphenol A: implications for toxicity testing. Toxicology 2013; 311: 13-26.

30. Llop S, Lopez-Espinosa MJ, Rebagliato M, Ballester F. Gender differences in the neurotoxicity of metals in children. Toxicology 2013; 311 : 3-12. 